\title{
Release of selected amino acids from zinc carriers
}

\author{
RENATA DYJA ${ }^{1 *}$ \\ BARBARA DOLIŃSKA ${ }^{1,2}$ \\ FLORIAN RYSZKA ${ }^{2}$ \\ ${ }^{1}$ Department of Applied \\ Pharmacy and Drug Technology \\ Medical University of Silesia \\ 41-200 Sosnowiec, Poland \\ ${ }^{2}$ Pharmaceutical Research and \\ Product Plant »Biochefa« \\ 41-200 Sosnowiec, Poland
}

Accepted February 16, 2016

Published online May 19, 2016

\begin{abstract}
The paper deals with the results of an investigation of the release of selected amino acids (histidine, tryptophan, tyrosine) from model suspensions prepared by co-precipitation with zinc chloride. It has been proven that the influence of the $\mathrm{Zn}(\mathrm{II}) / \mathrm{amino}$ acid molar ratio on dissolution profiles of the tested amino acids and dissolution half-life $\left(t_{1 / 2}\right)$ of histidine or tryptophan is significant. The amount of amino acid in the dispersed phase (supporting dose) is a determinant of the amino acid release profile. There is a minimal supporting dose $(30.0 \mu \mathrm{mol}$ of histidine or 17.4 $\mu$ mol of tryptophan) that provides release of similar amounts of amino acid (4.1-4.6 $\mu \mathrm{mol}$ of histidine or 8.7-9.9 $\mu \mathrm{mol}$ of tryptophan) after the same time intervals. The tyrosine release profiles follow first order kinetics since the supporting dose $(0.9-11.2 \mu \mathrm{mol})$ is limited by the tyrosine low solubility in water.
\end{abstract}

Keywords: amino acids, zinc, suspensions, dissolution, kinetics

Zinc in conjunction with protein, peptides or low molecular weight substances in the form of suspension provides prolonged drug action (1-6). Co-precipitation with zinc salts is one of the methods for obtaining sustained release drug carriers $(4,5)$. Co-precipitation involves intercalation of a low-molecular weight drug molecule into layered zinc hydroxide, layered zinc hydroxide salt, or layered double hydroxide (4-7). Sparingly soluble zinc compounds form matrices for sustained release of p-coumaric acid, levodopa $(4,5)$. These carriers are biocompatible and are an attractive alternative to other sustained release drug formulations (5).

Amino acids (AAs) are used as model substances in studies on suspensions (6-9). AA bound in the dispersed phase is a model of the supporting dose that slowly releases the drug. $\mathrm{Zn}(\mathrm{II}) / \mathrm{drug}$ molar ratio determines the dissolution profile of a suspension prepared by the co-precipitation method $(3,8)$.

On the basis of preliminary experiments, optimal variants of suspensions were obtained by co-precipitation of selected amino acids with zinc chloride. The most probable compound formed under the conditions reported in the paper is layered zinc hydroxide

\footnotetext{
*Correspondence; e-mail: rdyja@sum.edu.pl
} 
salt. AAs-histidine (His), tryptophan (Trp) and tyrosine (Tyr) served as model substances. Influence of the $\mathrm{Zn}(\mathrm{II}) / \mathrm{AA}$ molar ratio on the release of AA from suspensions was investigated. Due to their aromatic structure, the tested AA could be easily determined by the spectrophotometric method.

\section{EXPERIMENTAL}

Materials

L-Histidine (His, $\mathrm{C}_{6} \mathrm{H}_{9} \mathrm{~N}_{3} \mathrm{O}_{2}, \geq 99 \%$ pure; $\left.M_{\mathrm{r}}=155.15\right)$, L-tryptophan $\left(\operatorname{Trp} \mathrm{C}_{11} \mathrm{H}_{12} \mathrm{~N}_{2} \mathrm{O}_{2}\right.$ $\geq 98 \%$ pure; $\left.M_{\mathrm{r}}=204.23, \mathrm{pI}=5.89\right)$ and L-tyrosine $\left(\operatorname{Tyr} \mathrm{C}_{9} \mathrm{H}_{11} \mathrm{NO}_{3}, \geq 98 \%\right.$ pure; $M_{\mathrm{r}}=181.19$, $\mathrm{p} I=5.66)$ were purchased from Sigma Chemical Corp., USA. All other reagents were supplied by Avantor Performance Materials Poland S.A., Poland (formerly POCH, Poland). The reagents satisfied the requirements of the standards.

\section{Preparation of AA-Zn(II) suspensions}

AA (His, Trp or Tyr) was dissolved in $0.015 \mathrm{~mol} \mathrm{~L}^{-1} \mathrm{HCl}$ solution. Amount of $0.75 \mathrm{~mL}$ of $0.1 \mathrm{~mol} \mathrm{~L}^{-1} \mathrm{ZnCl}_{2}$ in $0.003 \mathrm{~mol} \mathrm{~L}^{-1} \mathrm{HCl}$ solution was mixed with $5 \mathrm{~mL}$ of $0.001,0.005,0.006$, 0.01 or $0.02 \mathrm{~mol} \mathrm{~L}^{-1} \mathrm{AA}$ solution yielding $\mathrm{Zn}(\mathrm{II}) / \mathrm{AA}$ molar ratios 15:1, 3:1, 2.5:1, 1.5:1 or 0.75:1, respectively. 0.75:1 $\mathrm{Zn}(\mathrm{II}) /$ Tyr molar ratio was not obtained because of the limited solubility of Tyr in $0.015 \mathrm{~mol} \mathrm{~L}^{-1} \mathrm{HCl}$. Then, $1.05-1.35 \mathrm{~mL}$ of $0.2 \mathrm{~mol} \mathrm{~L}^{-1} \mathrm{NaOH}$ solution was added. The volume of added $0.2 \mathrm{~mol} \mathrm{~L}^{-1} \mathrm{NaOH}$ solution provided the optimal $\mathrm{pH}$ value for AA binding in the dispersed phase and was determined on the basis of preliminary experiments. Total volume was adjusted to $10.0 \mathrm{~mL}$ with distilled water. The suspensions were stirred using a magnetic stirrer at $500 \mathrm{rpm}$ for $25 \mathrm{~min}$. The suspensions were then left at room temperature for $1 \mathrm{~h}$.

\section{Optical microscopy of $A A-Z n(I I)$ suspensions}

Optical microscope (MT 4000 Series Meiji Techno Co. LTP, Japan) was used to study the particle size of the suspension. A drop of undiluted formulation was viewed using total magnification of 100 or $400 \times$.

\section{Characterization of $A A-Z n(I I)$ suspensions}

The suspensions $(10 \mathrm{~mL})$ were centrifuged for 10 minutes at $4000 \mathrm{rpm}$. The $\mathrm{pH}$ values, concentrations of $\mathrm{AA}$ and $\mathrm{Zn}$ (II) were then determined in the supernatant. The amounts of AA (supporting dose) and $\mathrm{Zn}(\mathrm{II})$ in the dispersed phase were calculated as the difference between the initial amount and those determined in the supernatant. The precipitate was intended for use in the in vitro release study of AA.

In vitro release study of $A$ A from suspensions

The precipitate was re-suspended in $10 \mathrm{~mL}$ of $0.9 \% \mathrm{NaCl}$ solution and stirred with a magnetic stirrer at $500 \mathrm{rpm}$ for $30 \mathrm{~min}$. The suspension was subjected to centrifugation at $4000 \mathrm{rpm}$ for $10 \mathrm{~min}$ and the amount of dissolved AA was determined in the supernatant. 
The precipitate was re-suspended in $10 \mathrm{ml}$ of fresh $0.9 \% \mathrm{NaCl}$ solution and the procedure was repeated. The study was carried out until dissolution of $95 \%$ of the AA supporting dose or for $5 \mathrm{~h}$.

\section{Spectrophotometric determination of $A A$}

Absorbance $(x)$ was measured in $1 \mathrm{~cm}$ quartz cuvettes using a CE $3021 \mathrm{UV}-\mathrm{Vis}$ spectrometer (Cecil, UK). The photometric accuracy of the spectrophotometer was \pm 0.005 . AA concentration $(y)$ was calculated on the basis of regression equations (His $y=0.0387 x+$ $0.0053 R^{2}>0.999 ; \operatorname{Trp} y=0.1758 x+0.0087 R^{2}>0.999$; Tyr $y=0.0466 x+0.0256 R^{2}>0.999$ ). Absorbance was measured at wavelengths $\left(\lambda_{\max }\right)$ at which maximum absorbance was observed $\left(\lambda_{\max }(\right.$ His $\left.)=211.0 \mathrm{~nm}, \lambda_{\max }(\operatorname{Trp})=218.5 \mathrm{~nm}, \lambda_{\max }(\operatorname{Tyr})=222.5 \mathrm{~nm}\right)$.

\section{Complexometric determination of $\mathrm{Zn}(\mathrm{II})$}

$\mathrm{Zn}$ (II) was determined by complexometric titration using $0.05 \mathrm{~mol} \mathrm{~L}^{-1}$ EDTA in the presence of Eriochrome Black $\mathrm{T}$ in $\mathrm{pH} 10$ ammonia buffer until the initially violet solution turned blue (Polish Pharmacopeia VI).

\section{Determination of $\mathrm{pH}$ values}

$\mathrm{pH}$ values were measured using a Microcomputer $\mathrm{pH}$-meter CP-315 (POCH, Poland). The electrode was calibrated using $0.05 \mathrm{~mol} \mathrm{~L}^{-1}$ sodium phosphate buffer solution purchased in Chempur, Poland.

\section{Analysis of $A A$ release data}

The release kinetics of AA from the suspensions were elucidated by fitting the release data to kinetic models (first order or zero order) (Table I) and by comparison of the squared correlation coefficients $R^{2}$ values. AA dissolution half-lives $\left(t_{1 / 2}, \mathrm{~h}\right)$ were calculated according to the kinetics with the higher value of $R^{2}$ (Table I).

Table I. First order kinetics, zero order kinetics and Korsmeyer-Peppas equations (10)

\begin{tabular}{cccc}
\hline & First order kinetics & Zero order kinetics & Korsmeyer-Peppas model \\
\hline Linear equation & $\ln (100-\mathrm{Q})=-k_{1} t+\ln 100$ & $Q=k_{\mathrm{o}} t$ & $\ln \left(M_{\mathrm{t}} / M_{\infty}\right)=\ln k+n \ln t$ \\
$t_{1 / 2}$ & $t_{1 / 2}=0.693 / k_{1}$ & $t_{1 / 2}=50 / k_{\mathrm{o}}$ & \\
\hline
\end{tabular}

$Q$ - percent of AA released after time $I(\mathrm{~h}) ; k_{1}$ - first order release constant $(1 / \mathrm{h}) ; k_{\mathrm{o}}-$ zero order release constant $(\% / \mathrm{h}), t_{1 / 2}$ - dissolution half-life $(\mathrm{h}), M_{\mathrm{t}} / M_{\infty}$ - fraction of AA released at time $t(\mathrm{~h}) ; n-$ Korsmeyer-Peppas diffusion exponent.

\section{Data analysis}

The results were presented as the mean value $(x \pm S D)$ of 5 experiments and were analyzed using Excel (Microsoft Office) and Statistica 10 (Statsoft) computer programs. The influence of $\mathrm{Zn}(\mathrm{II}) / \mathrm{AA}$ on selected parameters was analyzed using ANOVA and Tukey's 
post-hoc test. The influence of the $\mathrm{Zn}$ (II)/AA molar ratio on dissolution profiles of AA was analyzed using ANOVA. The level of statistical significance was $p<0.05$.

\section{Determination and evaluation of theoretical $A A$ release profiles}

Theoretical AA release profiles were determined on the basis of the plot of the amount of AA released after the first $0.5 \mathrm{~h}$ against the amount of AA in the dispersed phase (AA supporting dose). Theoretical amount of AA released after the $0.5 \mathrm{~h}$ interval $(y)$ corresponded to the remaining amount of AA (new supporting dose) $(x)$. Similarity of theoretical and empirical AA release profiles was tested by means of relative error $\delta_{x}$, which was calculated by the equation:

$$
\delta_{x}=\frac{100 \times \sum_{j=1}^{\mathrm{n}}\left|x_{\mathrm{j}}-y_{\mathrm{j}}\right|}{\sum_{j=1}^{\mathrm{n}} x_{\mathrm{j}}}, \text { where }
$$

$j$ is a number of time points, $n$ is a total number of time points, $x_{j}$ is amount of AA released during $0.5 \mathrm{~h}$ at time point $j(\%)$ (curve 1) and $\mathrm{y}_{\mathrm{j}}$ is amount of AA released during $0.5 \mathrm{~h}$ at time point $j(\%)$ (curve 2).

Dissolution profiles were also compared using a model independent method. Fit factors- $f_{1}{ }^{\prime}$ (difference factor) and $f_{2}$ (similarity factor) were calculated by the equations:

$$
\begin{gathered}
f_{1}{ }^{\prime}=\frac{100 \times \sum_{j=1}^{\mathrm{n}}\left|R_{\mathrm{j}}-T_{\mathrm{j}}\right|}{\sum_{j=1}^{\mathrm{n}}\left(R_{\mathrm{j}}+T_{\mathrm{j}}\right) / 2}, \\
f_{2}=50 \times \log \left\{\left[1+(1 / n) \sum_{j=1}^{n}\left|R_{\mathrm{j}}-T_{\mathrm{j}}\right|^{2}\right]^{-0,5} \times 100\right\}
\end{gathered}
$$

where $j$ is a number of time points, $n$ is a total number of time points, $R_{\mathrm{j}}$ and $T_{\mathrm{j}}$ are cumulative percent of AA dissolved at each time point (curve 1 and curve 2, respectively).

According to the FDA guide for industry, $f_{1}{ }^{\prime}$ values up to $15(0-15)$ and $f_{2}$ values greater than 50 (50-100) ensure sameness or equivalence of the two curves (11).

\section{RESULTS AND DISCUSSION}

Properties of the obtained suspensions ( $\mathrm{pH}$ value, AA and $\mathrm{Zn}(\mathrm{II})$ concentration in the dispersed phase and particle size) are summarized in Table II.

Parenteral suspensions with protein-peptide hormones should be in the $\mathrm{pH}$ range 7.10-7.50. For research purposes and in order to obtain suspensions with the optimal amount of AA bound in the dispersed phase, the extended $\mathrm{pH}$ range was applied. Percent of AA bound in the dispersed phase was 57.3-84.4\% (His), 48.4-84.4\% (Trp) and 17.0-36.1\% (Tyr). The $\mathrm{pH}$ values that provided optimal variants of suspensions were 8.24-9.90 (His), 
Table II. Properties of the AA-Zn(II) suspensions

\begin{tabular}{cccccccc}
\hline AA & $\begin{array}{c}\text { Zn(II)/AA } \\
\text { molar ratio }\end{array}$ & $\begin{array}{c}c(\mathrm{AA}) \\
\left(\mathrm{mmol} \mathrm{L}^{-1}\right)^{\mathrm{a}}\end{array}$ & $\begin{array}{c}c(\mathrm{Zn}(\mathrm{II})) \\
(\mathrm{mmol} \mathrm{L})^{\mathrm{a}}\end{array}$ & $\mathrm{pH}$ & $\begin{array}{c}\mathrm{AA}_{\mathrm{b}} \\
\left(\mathrm{mmol} \mathrm{L}^{-1}\right)^{\mathrm{b}}\end{array}$ & $\begin{array}{c}\mathrm{Zn}(\mathrm{II})_{\mathrm{b}} \\
\left(\mathrm{mmol} \mathrm{L}^{-1}\right)^{\mathrm{b}}\end{array}$ & $\begin{array}{c}\text { Particle size } \\
(\mu \mathrm{m})\end{array}$ \\
\hline \multirow{4}{*}{ His } & $15: 1$ & 0.5 & 7.5 & $8.24 \pm 0.02$ & $0.3 \pm 0.0$ & $7.1 \pm 0.2$ & $1-5$ \\
& $3: 1$ & 2.5 & 7.5 & $9.82 \pm 0.02$ & $1.7 \pm 0.0$ & $6.2 \pm 0.0$ & $1-5$ \\
& $1.5: 1$ & 5.0 & 7.5 & $9.33 \pm 0.03$ & $4.2 \pm 0.0$ & $7.1 \pm 0.0$ & $<1$ \\
& $0.75: 1$ & 10.0 & 7.5 & $9.90 \pm 0.00$ & $5.7 \pm 0.1$ & $5.1 \pm 0.2$ & $<1$ \\
\hline \multirow{4}{*}{ Trp } & $15: 1$ & 0.5 & 7.5 & $7.01 \pm 0.00$ & $0.2 \pm 0.0$ & $6.0 \pm 0.0$ & $1-5$ \\
& $3: 1$ & 2.5 & 7.5 & $7.34 \pm 0.03$ & $1.2 \pm 0.0$ & $6.2 \pm 0.0$ & $1-5$ (aggregates 1-5) \\
& $2.5: 1$ & 3.0 & 7.5 & $7.43 \pm 0.03$ & $1.7 \pm 0.0$ & $6.5 \pm 0.0$ & $1-5$ (aggregates 1-10) \\
& $1.5: 1$ & 5.0 & 7.5 & $7.48 \pm 0.02$ & $4.2 \pm 0.0$ & $6.7 \pm 0.0$ & $1-10$ (aggregates 1-10) \\
& $0.75: 1$ & 10.0 & 7.5 & $7.79 \pm 0.02$ & $8.3 \pm 0.1$ & $7.0 \pm 0.0$ & $1-25$ (aggregates 5-25) \\
\hline \multirow{4}{*}{ Tyr } & $15: 1$ & 0.5 & 7.5 & $7.91 \pm 0.02$ & $0.1 \pm 0.0$ & $7.2 \pm 0.0$ & $1-5$ \\
& $3: 1$ & 2.5 & 7.5 & $7.90 \pm 0.03$ & $0.9 \pm 0.1$ & $6.7 \pm 0.2$ & $1-5$ \\
& $1.5: 1$ & 5.0 & 7.5 & $7.98 \pm 0.05$ & $1.2 \pm 0.0$ & $6.2 \pm 0.0$ & 15 \\
\hline
\end{tabular}

a initial concentration

${ }^{\mathrm{b}}$ concentration of amino acid or $\mathrm{Zn}(\mathrm{II})$ bound in the dispersed phase

7.01-7.79 (Trp) and 7.90-7.98 (Tyr) (Table II). The amount of $\mathrm{Zn}(\mathrm{II})$ bound (\%) as the matrix of the dispersed phase was higher than $79 \%$ (except for $\mathrm{Zn}(\mathrm{II}) / \mathrm{His}$ 0.75:1 suspension) (Table II).

The particle size of the dispersed phase of $\mathrm{Zn}(\mathrm{II}) / \mathrm{His} 15: 1,3: 1, \mathrm{Zn}(\mathrm{II}) / \mathrm{Tyr} 15: 1,3: 1$ and 1.5:1 and $Z \mathrm{n}(\mathrm{II}) / \operatorname{Trp} 15: 1$ suspensions was $1-5 \mu \mathrm{m}$ and was smaller than $1 \mu \mathrm{m}$ in the case of $\mathrm{Zn}(\mathrm{II}) / \mathrm{His} 1.5: 1$ and $\mathrm{Zn}(\mathrm{II}) /$ His $0.75: 1$ suspensions. Zn(II)/Trp 3:1, 2.5:1, 1.5:1, 0.75:1 suspensions included, besides amorphous particles, ordered spherical aggregates with particle sizes 1-25 $\mu \mathrm{m}$ (Table II).

Fig. 1 depicts the influence of the amount of AA in the dispersed phase (supporting dose) on the amount of AA released from suspensions after $0.5 \mathrm{~h}$. Theoretical AA release profiles were calculated on the basis of Fig. 1.

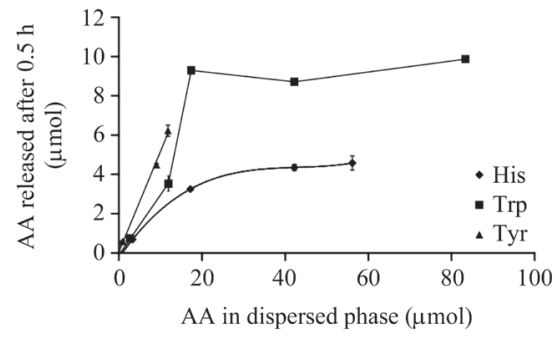

Fig. 1. The amount of AA released from suspensions after $0.5 \mathrm{~h}$ against the amount of AA in the dispersed phase (supporting dose). Theoretical AA release profiles were calculated on the basis of the graph. 
Suspensions with 30-57 $\mu \mathrm{mol} \mathrm{His} \mathrm{and} \mathrm{17-83} \mu \mathrm{mol}$ Trp in the dispersed phase released similar amounts of AA after $0.5 \mathrm{~h}(4.1-4.6 \mu \mathrm{mol}$ His and 8.7-9.9 $\mu \mathrm{mol}$ Trp). Suspensions with smaller amounts of AA in the dispersed phase released smaller amounts of AA after $0.5 \mathrm{~h}$. However, the amount of Tyr released after $0.5 \mathrm{~h}$ was directly proportional to the amount of Tyr in the dispersed phase (Fig. 1).

Fig. 2 shows AA release profiles and Fig. 3 shows cumulative AA release profiles. Theoretical AA release profiles (calculated from Fig. 1) are also marked (Figs. 2 and 3). Relative error values $\delta_{\mathrm{x}}<20 \%$ and fit factor values $\left(f_{1}^{\prime}<15\right.$ and $\left.f_{2}>50\right)$ confirmed the similarity of theoretical and empirical AA release profiles. This indicates that the amount of AA in the dispersed phase (maintenance dose) is the factor determining the AA release profile.
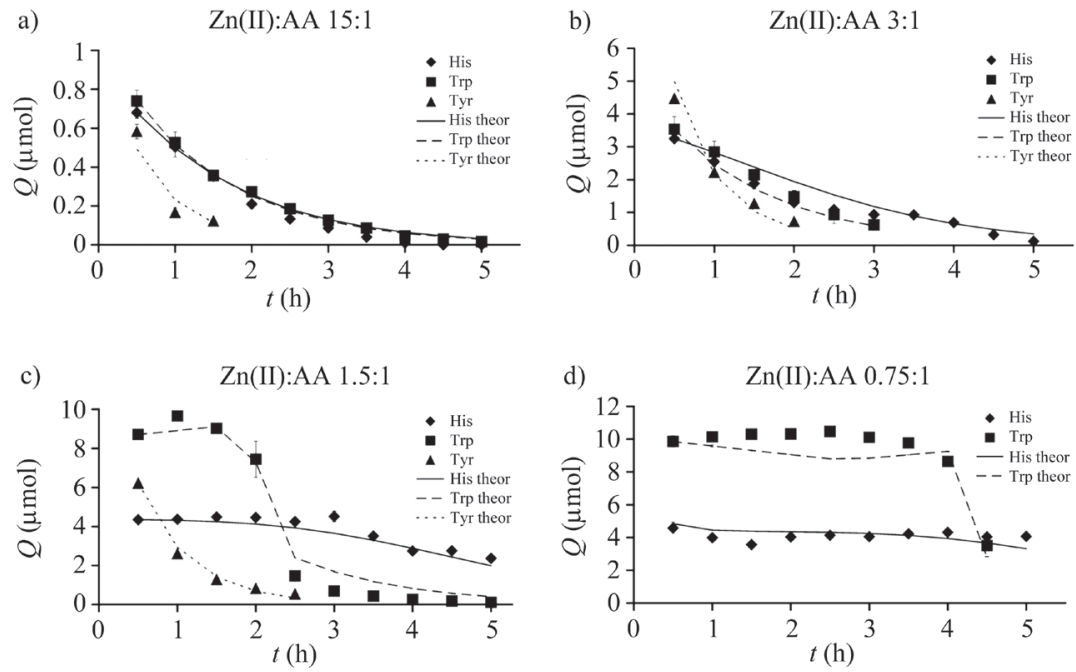

Fig. 2. The amount of AA $(\mathrm{Q}(\mu \mathrm{mol}))$ released over $0.5 \mathrm{~h}$ at specific time points. Suspensions with different $\mathrm{Zn}(\mathrm{II}) / \mathrm{AA}$ molar ratios: a) Zn(II)/AA 15:1, b) Zn(II)/AA 3:1, c) Zn(II)/AA 1.5:1 and d) Zn(II)/AA 0.75:1. Lines mark theoretical AA release profiles.

ANOVA showed a significant effect of the $\mathrm{Zn}(\mathrm{II}) / \mathrm{AA}$ molar ratio on the cumulative AA release $(\%)(p<0.05)$.

Kinetic analysis of the AA release data (first order and zero order $R^{2}$ squared coefficients, $t_{1 / 2}(\mathrm{~h})$ and Korsmeyer-Peppas diffusion exponent $n$ values) is given in Table III. The data calculated from the theoretical dissolution profiles are also summarized in Table III (in parentheses).

Release kinetics (zero order or first order) was determined on the basis of the $R^{2}$ correlation coefficients and Korsmeyer-Peppas diffusion exponent $n$ values (Table III). Korsmeyer-Peppas diffusion exponent $n$ value equal to 1.0 is indicative of zero order kinetics (10). Release of AA from the $\mathrm{Zn}(\mathrm{II}) / \mathrm{His} 0.75: 1\left(R^{2}=0.9995, n=0.96\right), \mathrm{Zn}(\mathrm{II}) / \mathrm{His} 1.5: 1\left(R^{2}=\right.$ 

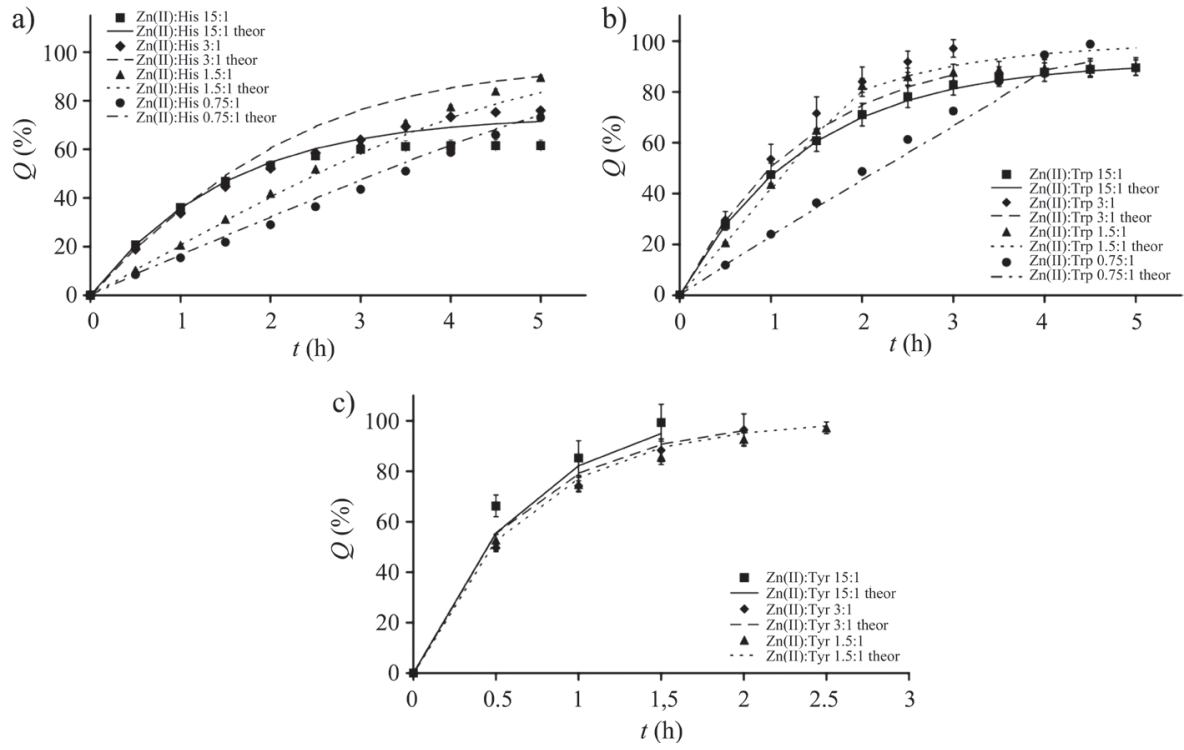

Fig. 3. Cumulative AA release profiles $Q$ (\%) vs.t(h); suspensions with different $\mathrm{Zn}(\mathrm{II}) / \mathrm{AA}$ molar ratios for: a) His, b) Trp and c) Tyr. Lines mark theoretical AA release profiles.

Table III. Kinetic analysis of the in vitro release data of His, Trp and Tyr from suspensions; values of $\mathrm{R}^{2}$ correlation coefficients, $\mathrm{t}_{1 / 2}(h)$ and Korsmeyer-Peppas diffusion exponent $n$ calculated from the theoretical dissolution profiles (in parentheses)

\begin{tabular}{cccccc}
\hline \multirow{2}{*}{ AA } & $\begin{array}{c}\text { Zn(II)/AA } \\
\text { molar ratio }\end{array}$ & $\begin{array}{c}\text { first order } \\
\text { kinetics }\end{array}$ & $\begin{array}{c}\text { zero order } \\
\text { kinetics }\end{array}$ & $t_{1 / 2}(\mathrm{~h})$ & $\begin{array}{c}\text { Korsmeyer-Peppas } \\
\text { diffusion exponent } \\
n\end{array}$ \\
\cline { 3 - 4 } & $15: 1$ & $0.324(0.795)$ & $0.000(0.216)$ & $2.77 \pm 0.17(2.31)$ & $0.45(0.52)$ \\
\multirow{2}{*}{ His } & $3: 1$ & $0.950(0.998)$ & $0.575(0.699)$ & $2.15 \pm 0.02(1.48)$ & $0.59(0.68)$ \\
& $1.5: 1$ & $0.926(0.956)$ & $0.982(0.987)$ & $2.59 \pm 0.02(2.86)$ & $0.96(0.97)$ \\
& $0.75: 1$ & $0.937(0.950)$ & $>0.999(>0.999)$ & $3.43 \pm 0.04(3.65)$ & $0.96(1.01)$ \\
\hline \multirow{3}{*}{ Trp } & $15: 1$ & $0.924(0.934)$ & $0.094(0.050)$ & $1.33 \pm 0.18(1.37)$ & $0.51(0.49)$ \\
& $3: 1$ & $0.944(0.999)$ & $0.703(0.613)$ & $0.71 \pm 0.12(1.01)$ & $0.65(0.57)$ \\
& $1.5: 1$ & $0.758(0.987)$ & $0.092(0.387)$ & $1.21 \pm 0.16(0.93)$ & $0.61(0.65)$ \\
& $0.75: 1$ & $0.735(0.873)$ & $0.993(0.992)$ & $2.14 \pm 0.02(2.30)$ & $0.99(0.95)$ \\
\hline \multirow{3}{*}{ Tyr } & $15: 1$ & $0.986(0.972)$ & $0.000(0.190)$ & $0.35 \pm 0.07(0.37)$ & $0.37(0.29)$ \\
& $3: 1$ & $0.971(0.998)$ & $0.161(0.000)$ & $0.48 \pm 0.09(0.43)$ & $0.48(0.41)$ \\
& $1.5: 1$ & $0.993(0.999)$ & $0.000(0.000)$ & $0.52 \pm 0.06(0.45)$ & $0.41(0.40)$ \\
\hline
\end{tabular}


$0.982, n=0.96)$ and $\mathrm{Zn}(\mathrm{II}) / \operatorname{Trp} 0.75: 1\left(R^{2}=0.993, n=0.99\right)$ suspensions followed zero order kinetics, since the suspensions with higher AA supporting dose $(>30.0 \mu \mathrm{mol}$ of His or $>$ $17.4 \mu \mathrm{mol}$ of Trp in the dispersed phase) released similar amounts of AA after $0.5 \mathrm{~h}$ (4.1-4.6 $\mu \mathrm{mol}$ of His or 8.7-9.9 $\mu \mathrm{mol}$ of Trp) (Fig. 1). Release of AA from the Zn(II)/His 15:1 or Zn(II)/ Trp 1.5:1 suspensions followed neither zero order nor first order kinetics (Table III). The release of His from $\mathrm{Zn}(\mathrm{II}) / \mathrm{His}$ 15:1 was incomplete (61.5 \%) (Fig. 3a). Release of Trp from the $\mathrm{Zn}(\mathrm{II}) / \operatorname{Trp}$ 1.5:1 suspension followed initially zero order kinetics (64.85\% of Trp supporting dose) as the amount of Trp in the dispersed phase was greater than $17.4 \mu$ mol during the first $2 \mathrm{~h}$. Trp release was then reduced as the amount of Trp in the dispersed phase dropped below $17.4 \mu \mathrm{mol}$ (Fig. 2c). In other cases, the release of AA from His-Zn(II), Trp-Zn(II) or Tyr-Zn(II) suspensions followed first order kinetics $\left(R^{2}>0.900\right.$ (Table III). No release of Tyr following zero order kinetics was obtained because of the small amount of Tyr in the dispersed phase (0.9-11.2 $\mu \mathrm{mol})$. Obtaining Tyr-Zn(II) suspensions with higher Tyr supporting dose was limited due to the low solubility of Tyr in water.

Release kinetics (zero order or first order) could be also determined on the basis of the theoretical AA release profiles; calculated $R^{2}$ values are summarized in Table III.

ANOVA showed a significant effect of the $\mathrm{Zn}(\mathrm{II}) / \mathrm{AA}$ molar ratio on the KorsmeyerPeppas diffusion exponent $n$ value in the case of all three AA $(p<0.05)$. However, $\mathrm{Zn}(\mathrm{II}) /$ His 1.5:1 and $\mathrm{Zn}(\mathrm{II}) / \mathrm{His}$ 0.75:1 suspensions $(p=0.93)$ or $\mathrm{Zn}(\mathrm{II}) / \operatorname{Trp} 3: 1$ and $\mathrm{Zn}(\mathrm{II}) / \operatorname{Trp} 1.5: 1$ suspensions ( $p=0.11$ ) had the same $n$ value. The $n$ values were close to 0.5 in case of all tested Tyr-Zn(II) suspensions $(n=0.37-0.48), \mathrm{Zn}(\mathrm{II}) / \mathrm{His} 15: 1$ suspension $(n=0.45)$ and $\mathrm{Zn}(\mathrm{II}) / \operatorname{Trp} 15: 1$ suspension $(n=0.51)$ indicating a Fickian diffusion mechanism (10). The $n$ values less than 0.5 can be explained by the release of AA removably adsorbed on the zinc hydroxide surface.

The $t_{1 / 2}$ values calculated according to the kinetics with higher $R^{2}$ value are summarized in Table III. ANOVA showed a significant effect $(p<0.05)$ of the $\mathrm{Zn}(\mathrm{II}) / \mathrm{AA}$ molar ratio on the $t_{1 / 2}$ value (His-Zn(II) or Trp-Zn(II) suspensions). However, $\mathrm{Zn}(\mathrm{II}) / \mathrm{AA} 1.5: 1$ and 15:1 Zn(II)/AA suspensions had the same $t_{1 / 2}$ value (His, $p=0.31$; Trp, $p=0.72$ ). $\mathrm{Zn}(\mathrm{II}) / \mathrm{Ty} r$ effect on the $t_{1 / 2}$ value was not significant $(p=0.08)$.

\section{CONCLUSIONS}

The amount of amino acid in the dispersed phase (supporting dose) is the determining factor of the release profile. There is a minimal supporting dose that provides the release of similar amounts of amino acid after the same time intervals (zero order kinetics).

Amino acid solubility in water is a limiting factor for obtaining suspensions with a supporting dose high enough to provide a release profile following zero order kinetics and sustained release. 


\section{REFERENCES}

1. U. Gietz, T. Arvinte, M. Häner, U. Aebi and H. P. Merkle, Formulation of sustained release aqueous Zn-hirudin suspensions, Eur. J. Pharm. Sci. 11 (2000) 33-41; DOI: 10.1016/S0928-0987(00)00072-5.

2. K. Shi, F. Cui, H. Bi, Y. Jang, H. Shi and T. Song, Metal ions guided self-assembly of therapeutic proteins for controllable release: from random to ordered aggregation, Pharm. Res. 30 (2013) 269279; DOI: 10.1007/s11095-012-0871-9.

3. B. Dolińska and F. Ryszka, Pulsatile and moderated release of dalareline from $\mathrm{Zn}$ (II) complexes in the form of suspension, Boll. Chim. Farmac. 142 (2003) 10-13.

4. T. Biswick, D. H. Park, Y. G. Shul, J. H. Choy, p-Coumaric acid-zinc basic salt nanohybrid for controlled release and sustained antioxidant activity, J. Phys. Chem. Solid. 71 (2010) 647-649; DOI: 10.1016/j.jpcs.2009.12.058.

5. A. U. Kura, S. H. Hussein Al-Ali, M. Z. Hussein, S. Fakurazi and P. Arulselvan, Development of a controlled release anti-parkinsonian nanodelivery system using levodopa as the active agent, Int. J. Nanomed. 8 (2013) 1103-1110; DOI: 10.2147/IJN.S39740.

6. C. G. Carbajal Arízaga, Intercalation studies of zinc hydroxide chloride: ammonia and amino acids, J. Solid State Chem. 185 (2012) 150-155; DOI: 10.1016/j.jssc.2011.11.016.

7. Á. Fudala, I. Pálinkó and I. Kiricsi, Preparation and characterization of hybrid organic-inorganic composite materials using the amphoteric property of amino acids: amino acid intercalated layered double hydroxide and montmorillonite, Inorg. Chem. 38 (1999) 4653-4658; DOI: 10.1021/ ic981176t.

8. B. Dolińska and F. Ryszka, The influence of physicochemical properties of amino acids on their release from the Zn(II)-amino acid complexes in suspension, Boll. Chim. Farm. 141 (2002) 218-222.

9. B. Dolińska, The properties of solid Zn(II)-amino acid complexes in the form of suspensions, Il Farmaco 56 (2001) 737-740.

10. S. Jose, J. F. Fangueiro, J. Smitha, T. A. Cinu, A. J. Chacko, K. Premaletha and E. B. Souto, Predictive modeling of insulin release profile from cross-linked chitosan microspheres, Eur. J. Med. Chem. 60 (2013) 249-253; DOI: 10.1016/j.ejmech.2012.12.011.

11. P. Costa and J. M. Sousa Lobo, Modeling and comparison of dissolution profiles, Eur. J. Pharm. Sci. 13 (2001) 123-133; DOI: 10.1016/S0928-0987(01)00095-1. 